\title{
Design and Implementation of the Knowledge Parts Library of Aeronautical Standard Parts Based on CATIA
}

\author{
Qiang $\mathrm{Li}^{1, \mathrm{a}}$, Yan $\mathrm{CaO}^{2, \mathrm{~b}}$, Jiang $\mathrm{Du}^{3, \mathrm{c}}$, Nana Zhang ${ }^{4, \mathrm{~d}}$ \\ 1,2,3,4 The Institute of Mechanical and Electrical Engineer, Xi'an Technological University, Xi'an \\ 710032 \\ a1107984512@qq.com, ${ }^{\mathrm{b}}$ jantonyz@163.com, ${ }^{\mathrm{c}}$ Simen_du@sina.com
}

Keywords: Parametric Design; CATIA; Standard Parts Library; Aviation Standard Parts

\begin{abstract}
With the object to reuse the design data and method of the aviation standard parts, the method to develop the knowledge parts library of aeronautical standard parts which can be expanded dynamically and seamless integrated with CATIA is researched with the MBD and parametric technology. Based on the research results of this paper, the automatic modeling of the corresponding aviation standard parts can be created according to the design goals or using requirements, so it can shorten the entire aviation standard parts' development cycle and improve the design efficiency of the products.
\end{abstract}

\section{Introduction}

A variety of new aircraft will be developed continuously according to the rapid development of china's aviation, so original aircraft need to be manufactured and redesigned. CATIA is the CAD / CAE / CAM integrated software of Dassault Company in France. It is a leader system in CAD / CAE / CAM field and be widely used in the fields of aerospace, automobile, shipbuilding, electrical and electronic products etc. Many national factories and institute all use the CATIA to define the digital products. Based on a large amount provided commonly parametric features, users can build their own parts library according to the characteristics of the product needs with CATIA. Firstly, this paper introduces the technology characteristics of the parametric modeling in CATIA and the methods to creating standard part library with CATIA. Then based on the CATIA own knowledge engineering module, the method to create the knowledge aviation standard parts library and correspond key technology such as the parametric modeling method, the model can package the design and process feature with MBD technology is researched through the $120^{\circ}$ countersunk screw.

\section{The Characteristics of the CATIA Parametric Modeling Technology and Its Methods to Create Standard Parts Library}

Parametric designs is a key issue in the application of CAD technology, through build the relation among the geometric structure and feature with the defined pragmatics, the model can be driven by the parametric through update the dimensions by changing the parametric value [1]. Compared with traditional design method, the superiority of parametric design method are shorter product design cycle, small repeated workload and high design efficiency, among which the greatest difference is that parametric design method memorize entire design procedure.

At present, there are three methods of establishing standard part library under CATIA V5 ${ }^{[2]}$ : Set up standard part library by using the secondary development interface of CATIA and VC development environment; (2) Add the library file of CATIA to program frame with the reference object library in VB and implement secondary development by quoting class object as well as; (3) Establish and use three-dimensional standard parts based on utilizing the Formula command, Design Table command and Catalog command provided by CATIA software.

During the design of aviation standard parts, it is inevitably to modify geometric dimension and structural shape repeatedly, expand other information of design technology of aviation standard 
parts, and implement comprehensive coordination as well as optimization. In order to avoid this simple "repeated" work, to set up the knowledge parts library of aeronautical standard parts that can create the basis of model packaging standard parts related design data and method is in urgent need. Based on CATIA parameterized model, further apply the geometric and non-geometric information of MBD technology defining surpassing structural dimension in model; then utilize CATIA knowledge engineering module and Catalog function to establish the knowledge parts library of aeronautical standard parts.

\section{Design Thinking and Key Technology of the Knowledge Parts Library of Aeronautical Standard Parts.}

The design flow of the knowledge parts library of aeronautical standard parts is as shown in Fig. 1:

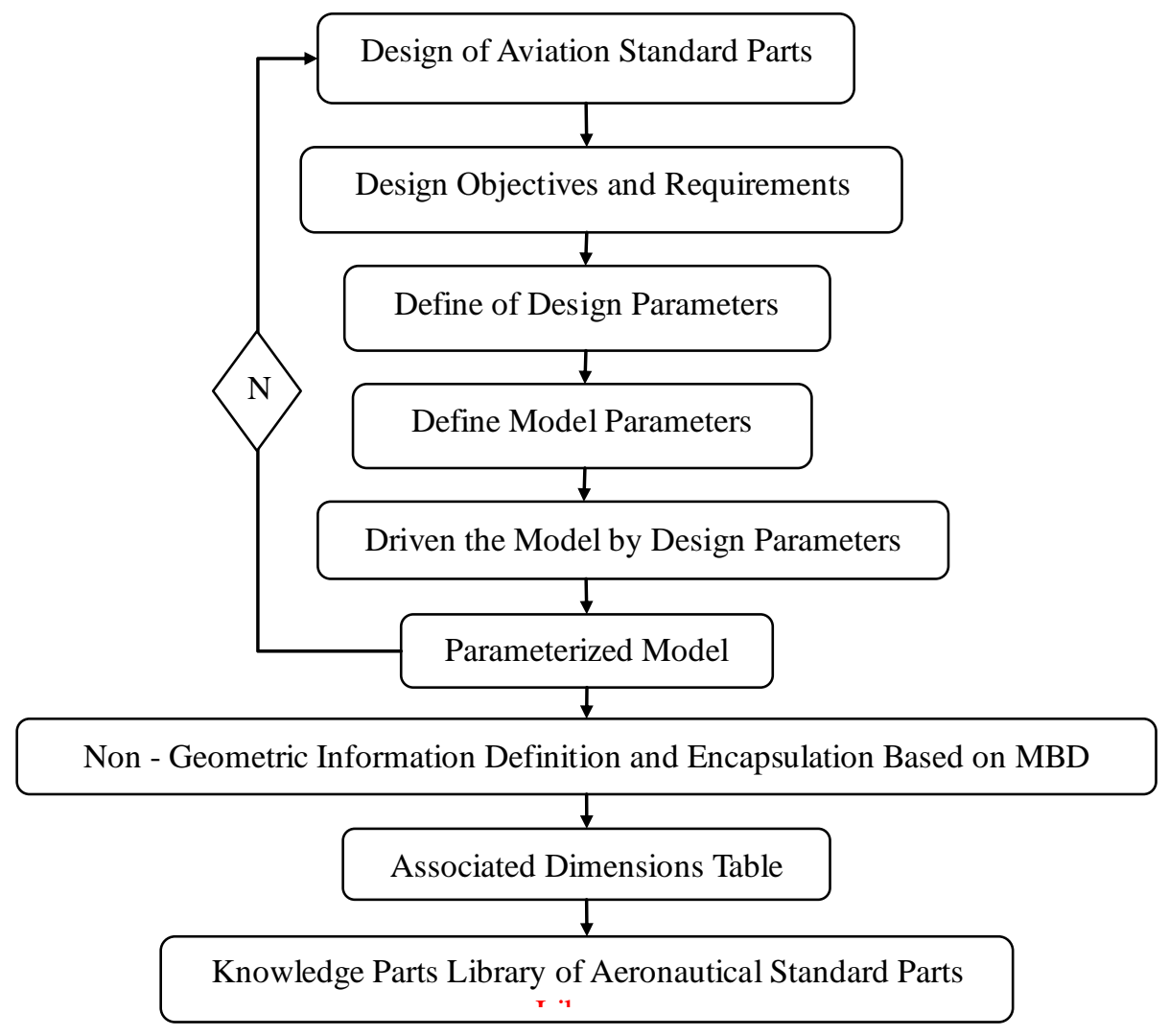

Figure 1. Design process of the knowledge parts library of aeronautical standard parts

The wide varieties of screw in aviation standard parts are all standardized. By taking the $120^{\circ}$ countersunk screw (HB1-207-1995) in aviation standard parts as example, this article carried out parametric modeling and established the knowledge parts library of aeronautical standard parts.

Design of Screw. According to the design method stipulated in mechanical design manual, the design objective and operating requirement of screws in practice mainly embody at load level. Thereupon, it is available to define screw functional parameter as $P$ (single screw shear failure load, ${ }^{N}$ ); its calculation relationship with screw diameter is as follows:

$$
\begin{aligned}
& P=\frac{f \pi d^{2}}{4} \\
& L_{1}=L-H
\end{aligned}
$$


$f$ is screw shear strength, $N / \mathrm{mm}^{2} ; d$ is screw nominal diameter, mm; $L_{1}$ is screw rod length, $\mathrm{mm} ; \quad L$ is screw length, $\mathrm{mm} ; H$ is nut height, $\mathrm{mm}$.

Based on the materials used for design, screw shear strength can be inquired; then input $P$ can calculate screw diameter; screw other structural parameters can be obtained from the corresponding diameter data in screw size specification.

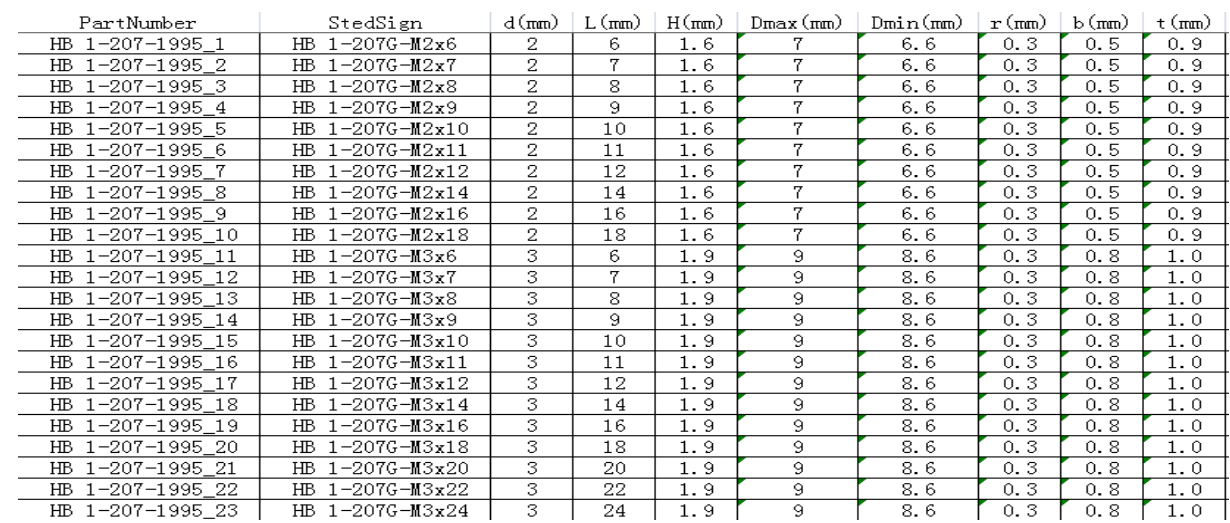

Figure 2. Screw dimensions table

Create Screw Parameters. Extract a group of driving variable parameters with basic features from spreadsheet; use the formula $\mathrm{f}(\mathrm{x})$ in intelligent menu to establish user parameter and express basic parts characteristic parameters; set up driving variable (parameter) characteristics number. Click toolbar f (x) to newly establish and select "length" and "individual"; with respect to other properties, select "character string" and "multiple value", input driving parameters, click application, and then input next variable; after finishing, click OK key to exit as shown in Fig. 3. Display variable parameter in characteristic tree as shown in Fig. 4.

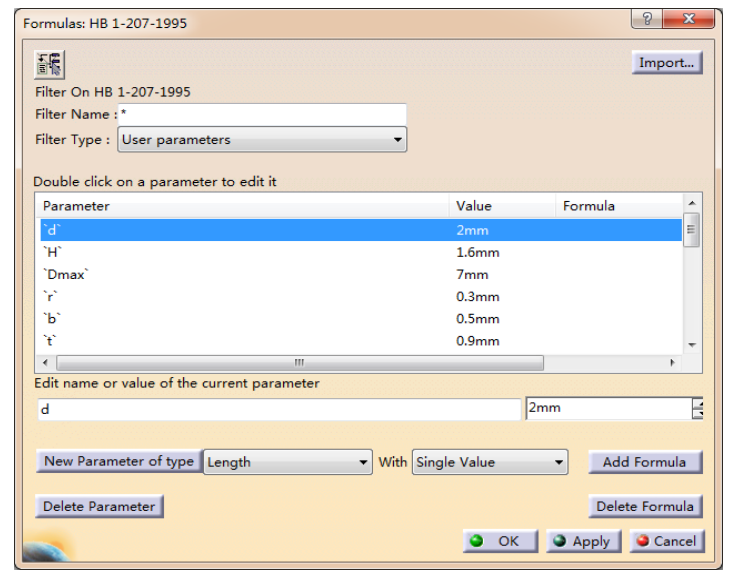

Figure 3. Define model parameters

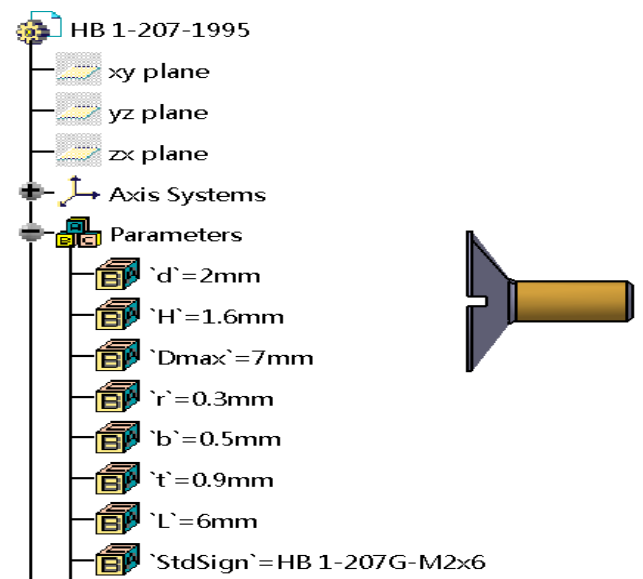

Figure 4. Characteristic parameters

Establishment of Screw Template. Apply the geometrical dimension defined above to establish parameterized three-dimensional standard parts template. Firstly, obtain screw model in the parts design module of CATIA through rotation, groove and chamfering tools; then restrain various drafts and parameterize based on the inputted parameters and through editing formula. As shown in Fig. 5. 


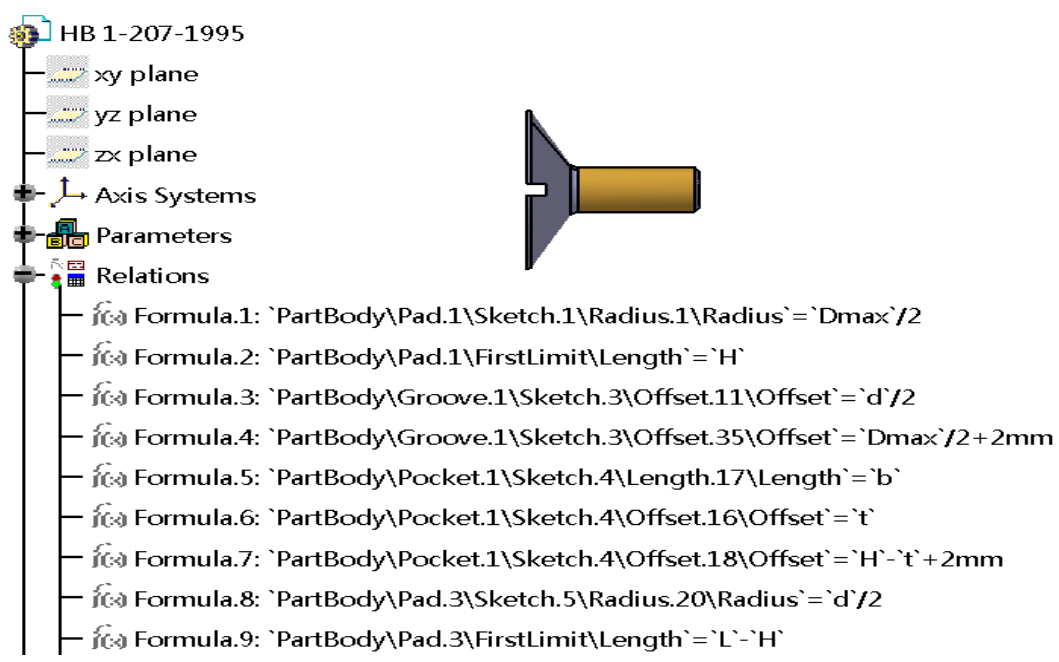

Figure 5. Screw (HB1-207-1995) model

Definition of Packaging and Model of Screw Design Technological Property. Implement packaging on screw design technological parameter by using model digitization definition technology. Correlate text document of screw design technological property with screw model, and upgrade the model. The ultimate screw design technological property is shown in Fig. 6.

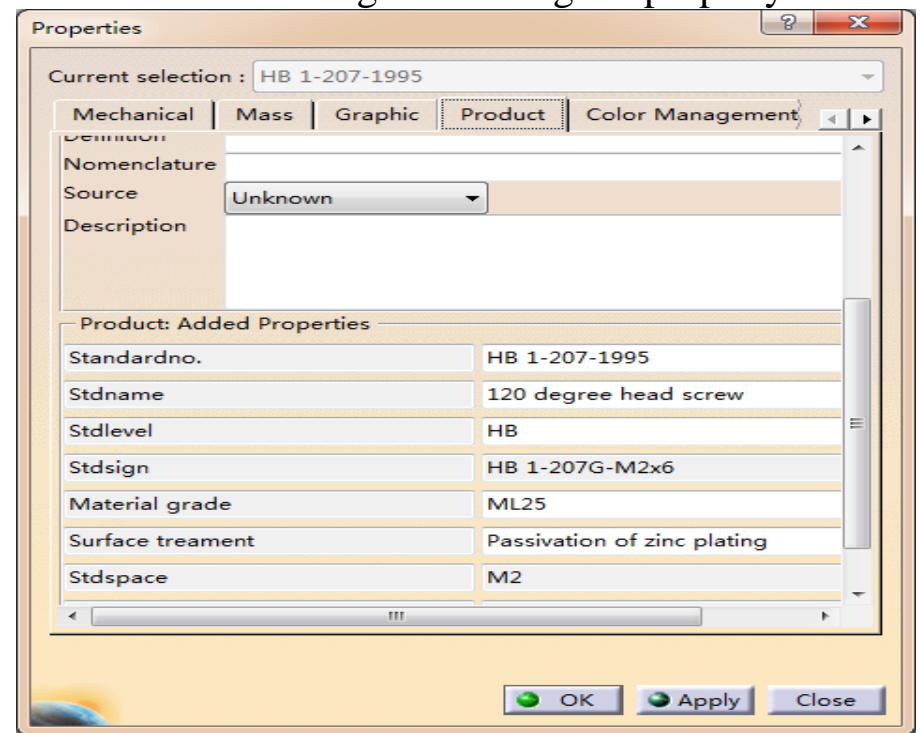

Figure 6. The ultimate screw design technological property

Except for including three-dimensional entity geometric information, screw MBD model also completely expresses all the non-geometric information for processing and using this part by means of labeling and property parameter data description. The structural specification of screw parts expresses all the geometric and non-geometric information of screw in the form of classification nodes. Generally, screws are achieved by numerical control processing, so the description node of parts specifies requirements of general geometric tolerance, appearance and surface treatment for parts processing [3]. Screw MBD model is shown in Fig. 7. 


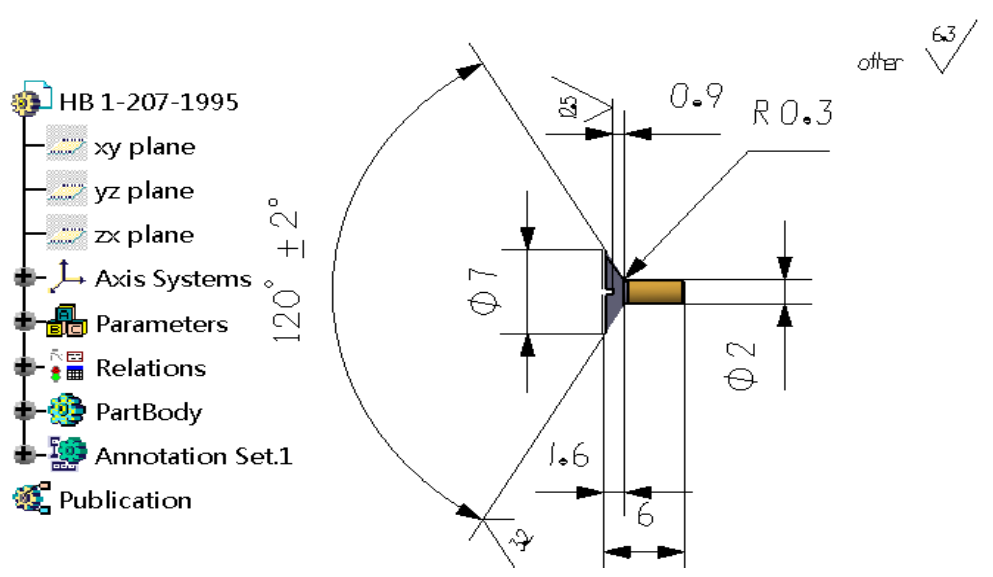

Figure 7 the MBD model of screw

Establishment of Knowledge Parts Library of Aeronautical Standard Parts. The architecture of knowledge parts library of aeronautical standard parts is shown in Fig 8.

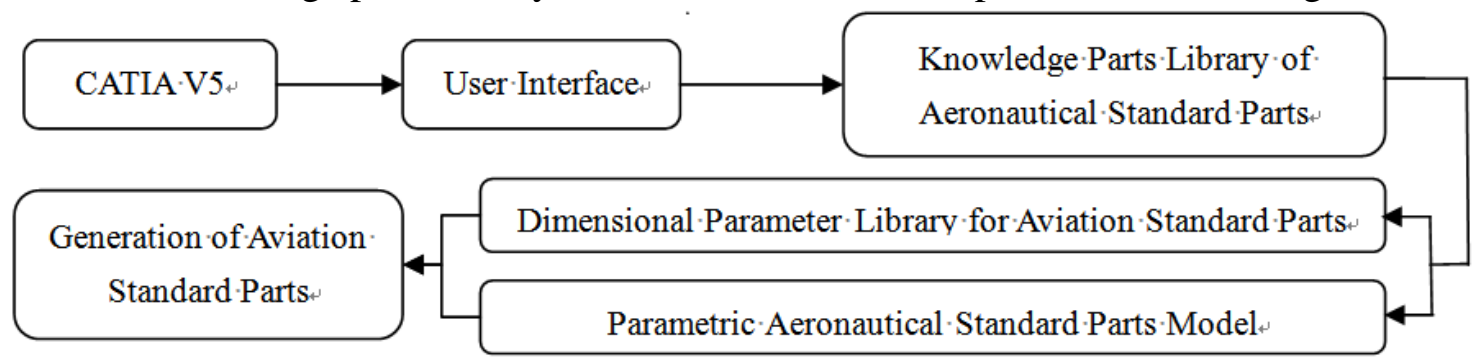

Figure 8. Architecture of the knowledge parts library of aeronautical standard parts

In order to establish screw standard parts library without any influence, hide the abovementioned labeling of MBD screw model, and display it when necessary. The management of knowledge parts library of aeronautical standard parts model is realized by the Catalog editing tool of CATIA. The function of Add Part Family imports the parameterized model, which is controlled by spreadsheet and knowledge engineering, into Catalog template and generates a series of preview pictures. This process is also named as "model storage". Meanwhile, as shown in Fig. 9, the maintenance of Knowledge parts library of aeronautical standard parts is also accomplished in Catalog editing environment, which, as needed, can expand or modify knowledge parts library of aeronautical standard parts conveniently so as to create facility for searching as well as invoking in the future.

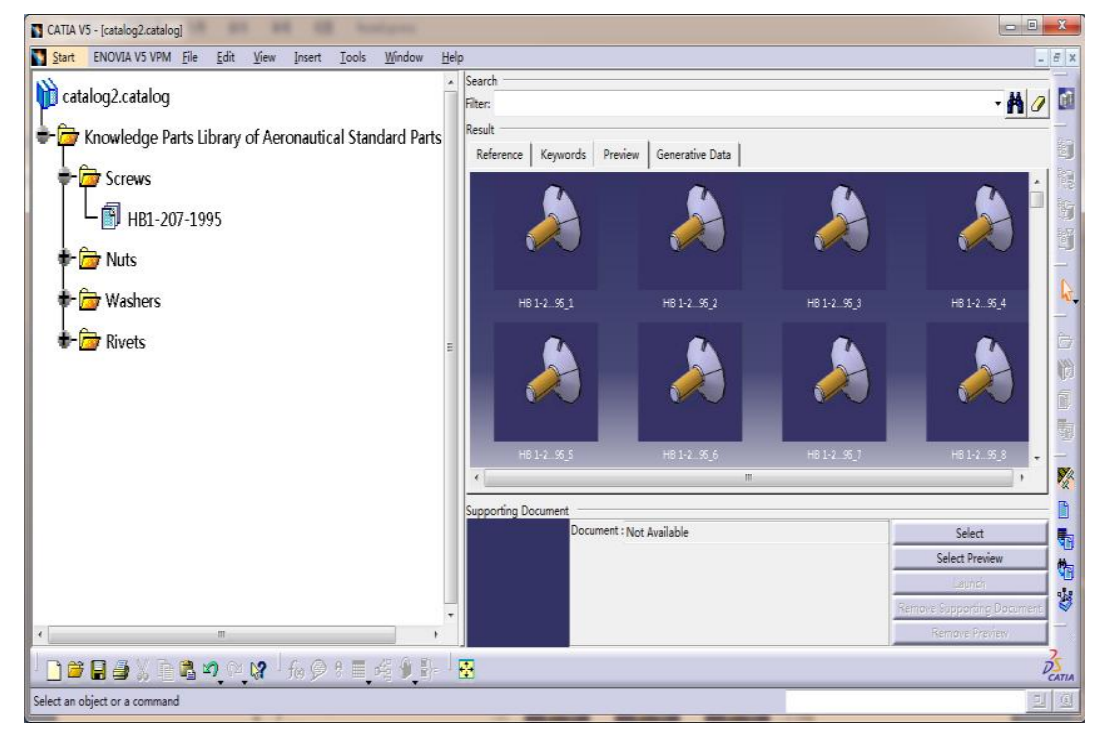

Figure 9. Knowledge parts library of aeronautical standard parts 
When it is necessary to invoke certain part, open Catalog document library, just double click the preview picture in Knowledge parts library of aeronautical standard parts directly to open the part required. If there is no corresponding part in inventory, the relevant aviation standard part can be obtained by finding the corresponding template of series aviation standard part and modifying the parameter.

\section{Conclusion}

By taking the improvement of design efficiency as well as quality of aviation standard parts as target, this article researched and established Knowledge parts library of aeronautical standard parts, which can achieve unified management of non-geometric information and three-dimensional model of aviation standard parts, such as name, category, material, weight, surface treatment, failure load and processing appearance requirement, etc. In addition, it can provide aviation standard parts three-dimensional model dynamically based on design requirement, which not only offers effective support to redesign of aviation standard parts, but also solves the problems of aviation standard parts in practical use, including tedious invoking and inquiry, and low design efficiency.

\section{Acknowledgment}

The paper is supported by Key Problem Tackling Project of Shaanxi Scientific and Technological Office (2016GY-024).

\section{Reference:}

[1] T.G. Zhang and B. Hao. Modeling Technology of Full Three-dimensional Parameters Based on MBD [J]. Group Technology and Production Modernization, Vol. 29 (2012) No.4, p.56. (In Chinese)

[2] C.L. Peng. Construction of Part Library of Aircraft Tooling Based on CATIA [J]. Aeronautical Manufacturing Technology, Vol. 516 (2010) No.21, p.79. (In Chinese)

[3] K.X. Wu and X.Shi. Research on the Application of MBD Technology to Aeronautical Digital Manufacturing [J]. Journal of Xi'an Aeronautical University, Vol. 33 (2015) No.1, p.24. (In Chinese)

[4] H. Lu, S. Han and Y.Q. Fan. Digital Definition Technology Based on Model [J]. Aeronautical Manufacturing Technology, Vol. 10 (2008) No.3, p.78. (In Chinese)

[5] H. Xue. The Study of Tooling Design Correlation Technology Based on Digital Parametric Design (MS, Shenyang Aerospace University, China 2014), p.1. (In Chinese)

[6] L. Yuan, H.B. Li and F.H. Guo. Parametric Modeling of Aircraft Landing Gear [J]. Aeronautical Manufacturing Technology, Vol. 10 (2010) No.18, p.94. (In Chinese)

[7] J. Liu and S.X. Tang. Work Load Analysis and Bolt Design in a Connected Mast. Mechanical [J]. Vol. 33 (2006) No.1, p.12. (In Chinese)

[8] L.Y. Fu, L. Zhong, T.J. Sheng and F.H. Tu. The Research on the Contact Pressure of Part Interface Connected by Small Bolt. Science Technology and Engineering [J]. Vol. 10 (2010) No.24, p.6100. (In Chinese)

[9] L.Z. Zhang, Y. Li and J.F. Yu. Research of Fulfillment of the Accompanied Knowledge Based System for Aircraft Assembly Design [J]. Aeronautical Manufacturing Technology, Vol. 10 (2009) No.20, p.76. (In Chinese)

[10]X.L. Zhang and M.H. Xu. A Full 3D Modeling Technology Based on MBD [J]. Avionics Technology, Vol. 46 (2015) No.4, p.18. (In Chinese) 